\title{
IMPLEMENTATION OF ZAKAT FUND EMPOWERMENT MODEL, INFAQ, SHADAQAH IN BADAN AMIL ZAKAT NASIONAL (BAZNAS) MADIUN CITY
}

\section{PENERAPAN MODEL PENDAYAGUNAAN DANA ZAKAT, INFAQ, SHADAQAH DI BADAN AMIL ZAKAT NASIONAL (BAZNAS) KOTA MADIUN}

\author{
Mohammad Dendi Abdul Nasir ${ }^{1}$ \\ ${ }^{1}$ UIN Sunan Kalijaga Yogyakarta) \\ dendinasir8@gmail.com
}

\begin{abstract}
Human needs are ever-increasing and developing. Therefore economic activity is inevitable and Islamic philanthropy has a crucial role in this development. Because some problems related to economic inequality and underdevelopment cannot be faced personally, it requires togetherness and cares especially economic interactions between muzak and mustahiq. National Alms Agency of Madiun city, as a pioneer related to such interaction, has a vital role in economic empowerment, especially for Madiun City. Because it becomes crucial to know the application of the zakat, infaq, and sadaqah fund utilization models because it can be one of the successes in minimizing economic inequality and underdevelopment, this research utilizes a descriptive method qualitative approach. There are five research subjects. The type of research data uses primary and secondary data type. Methods used in data collection include interviews, observation, document, and observation. This study shows that the activities of zakat, infaq, and sadaqah fund utilization models at the National Alms Agency of Madiun City took the form of consumptive distribution and productive distribution utilization. The utilization of traditional consumptive distribution in the form of calamity and disaster aid, and the creative utilization of consumptive distribution in the form of health assistance and educational assistance or scholarships. Whereas the utilization of productive distribution uses the surplus zakat budged model, where the collection of zakat funds is then distributed in part, and the rest is used for productive projects-utilization of productive distribution in the form of work tools business capital under BAZNAS Madiun City guidance.
\end{abstract}

Keywords: Zakat, Infaq, Sadaqah, National Alms Agency (BAZNAS) of Madiun City

\begin{abstract}
ABSTRAK
Kebutuhan manusia seiring berjalannya waktu terus-menerus bertambah dan mengalami perkembangan, oleh karena itu kegiatan ekonomi merupakan hal yang tidak bisa dihindarkan dan filantropi Islam memiliki peran yang sangat penting dalam perkembangan tersebut. Karena masalah terkait ketimpangan dan keterbelakangan ekonomi tidak bisa dihadapi secara pribadi, tetapi membutuhkan kebersamaan dan rasa saling peduli, terutama interaksi ekonomi antara muzakki dan mustahiq. BAZNAS Kota Madiun sebagai pionir terkait interaksi seperti itu memiliki peran penting dalam pemberdayaan ekonomi terutama bagi masyarakat Kota Madiun. Karena itu menjadi sangat penting untuk mengetahui penerapan model pendayagunaan dana zakat, infaq, dan shadaqah, karena itu bisa menjadi salah satu kesuksesan dalam meminimalisir ketimpangan dan keterbelakangan ekonomi. Penelitian ini menggunakan metode deskriptif dengan pendekatan kualitatif. Subjek penelitian ini ada lima. Jenis data penelitian dengan memanfaatkan jenis data primer dan sekunder. Dalam penelitian ini metode yang digunakan dalam pengumpulan data, yaitu antara lain: wawancara, observasi, dokumen dan pengamatan. Hasil penelitian ini menunjukkan bahwa kegiatan model pendayagunaan dana zakat, infaq, dan shadaqah di Badan Amil Zakat Nasional (BAZNAS) Kota Madiun berupa pendayagunaan distribusi konsumtif dan pendayagunaan
\end{abstract}


Vol. 4 No. 2 Sepember 2020

distribusi produktif. Dimana pendayagunaan distribusi konsumtif tradisional berupa bantuan musibah serta bencana, dan pendayagunaan distribusi konsumtif kreatif berupa bantuan kesehatan serta bantuan pendidikan atau beasiswa. Sedangkan pendayagunaan distirbusi produktif menggunakan model surplus zakat budged, dimana pengumpulan dana zakat yang kemudian dibagikan sebagian dan sisanya digunakan untuk proyek-proyek produktif. Pendayagunaan distirbusi produktif berupa bantuan alat kerja dan modal usaha binaan BAZNAS Kota Madiun.

Kata kunci: zakat, infaq, shadaqah, baznas madiun

\section{A. PENDAHULUAN}

Kegiatan ekonomi merupakan hal yang tidak dapat dipisahkan dari kehidupan manusia. Seiring perkembangan zaman, tentu kebutuhan terhadap manusia bertambah, oleh karena itu secara terusmenerus mengalami perkembangan. filantropi Islam memiliki peran penting dalam perekonomian.

Zakat disamping memiliki dimensi spiritual, juga memiliki dimensi sosialekonomi. Penerapan ajaran berzakat pada sisi psiko-spritual akan berdampak dalam mengeliminasi karakter keserakahan yang sering menjadi pemicu timbulnya problem sosial ekonomi dalam bentuk konflik sosial, terutama antara kelompok masyarakat elite dan kelompok masyarakat menengah kebawah (Mansur, 2014:130).

Selain zakat, infaq dan shadaqah pun juga mempunyai peranan penting dalam pengembangan ekonomi ummat. Dengan demikian Islam adalah agama yang menawarkan pandangan hidup yang seimbang dan bersinergis untuk mengantarkan kepada kebahagiaan hidup melalui aktualisasi keadilan sosio-ekonomi dan persaudaraan dalam masyarakat.
Di sisi lain, Islam juga mempunyai misi untuk menegakkan keharmonisan antara kebutuhan moral dan material. Islam menyampaikan ajaran bahwa untuk memenuhi kebutuhan hidupnya, manusia harus bekerja agar terhindar dari kemiskinan dan dapat mencukupi kebutuhan hidupnya, dan lebih lanjut agar dapat mengeluarkan zakat serta shadaqah (Khasanah, 2010:4).

Baznas Kota Madiun sebagai salah satu BAZDA tingkat kabupaten atau kota dalam pendayagunaan zakat, infaq, dan shadaqah yang telah banyak melakukan perubahan dan dijadikan solusi masalah perekonomian masyarakat Kota Madiun dengan programprogram yang berkualitas dan inovatif. Hal inilah yang mendorong diadakannya penelitian secara khusus di BASNAZ Kota Madiun.

Tujuan dari penelitian ini adalah untuk memahami pendayagunaan dana filantropi Islam yaitu zakat, infaq, dan shadaqah di Badan Amil Zakat nasional (BASNAS) Kota Madiun secara mendalam.

Terkait penelitian yang dilakukan, ditemukan beberapa hasil penelitian terdahulu yang menunjukkan adanya celah 
dalam hal pendayagunaan dana filantropi yang dilakukan oleh lembaga pengelola zakat. Antara lain:

1. Indah Pilayanti (2010) Transformasi Tradisi Filantropi Islam: Studi Model Pendayagunaan Zakat, Infaq, Sadaqah Waqaf di Indonesia. Economica. Nomor 11. Edisi 11. Adanya pemanfaatan dana filantropi Islam masih dikelola secara tradisional sehingga dampak positif terhadap penguatan ekonomi mustahiq yang berkelanjuttan belum maksimal.

2. Ririn Tri Puspa Ningrum (2016) Penerapan Manajemen Zakat dengan Sistem Revolving Fund Models Sebagai Upaya Efektifitas Penyaluran Zakat Produktif (Studi pada Lembaga Manajemen Infaq Madiun). ElWasathiya: Jurnal Studi Agama Volume 4. Nomor 1. Juni 2016; p-ISSN 2338-9648.e-ISSN: 2527631X. Dana filantropi sudah dikembangkan dengan manajemen pendayagunaan modern dengan system revolving fund model, namun nyatanya masih belum optimal

3. Fahami Muhammad Anis dan Salina $\mathrm{H}$. Kassim (2016) Effectiveness Of ZakatBased Programs On Poverty Alleviation And Economic Empowerment Of Poor Women: A Case Study Of Bangladesh. Journal of Islamic Monetary Economics and
Finance, Vol. 1, No.2, February 2016. Sistem zakat yang efektif mampu dijadikan sebagai media pemberdayaan ekonomi masyarakat miskin di daerah desa.

Celah tersebut menarik untuk diteliti supaya pendayagunaan dana filantropi Islam yaitu zakat, infaq, dan shadaqah dapat diterapkan dengan baik sehingga mampu menjadi media penguatan ekonomi mustahiq.

\section{B. TINJAUAN PUSTAKA}

\section{Pengertian Zakat, Infaq, dan Shadaqah}

a. Zakat

Zakat menurut syara', berarti hak yang wajib dikeluarkan dari harta. Harta yang dikeluarkan menurut syara', dinamakan zakat karena harta itu akan bertambah dan memelihara dari kebinasaan (Az-zuhaili, 1995: 83). Selain itu, zakat menurut syara' (istilah), adalah nama suatu ibadah wajib yang dilaksanakan dengan memberikan sejumlah kadar tertentu dari harta milik sendiri kepada orang yang berhak menerimanya menurut yang ditentukan syariat Islam (Kartika, 2007: 10).

Menurut Wahbah Az-zuhaili (2011) dalam kitab Al Fiqh Al Islam wa Adillatuh mengungkapkan beberapa definisi zakat menurut para ulama madzhab, diantaranya: 
1) Menurut Malikiyah, zakat adalah mengeluarkan sebagian tertentu dari harta tertentu yang telah sampai nishab kepada yang oeang berhak menerima, jika kepemilikian, haul (genap satu tahun) telah sempurna selain barang tambang, tanaman, dan harta temuan.

2) Menurut Hanafiyah, zakat adalah pemberian hak kepemilikan atas sebagian harta tertentu kepada orang tertentu yang telah ditentukan oleh syariat, sematamata karena Allah Subhanahu Wa Ta'ala.

3) Syafi'iyah mendefinisikan zakat adalah nama untuk barang yang dikeluarkan untuk harta atau badan (diri manusia untuk zakat fitrah) kepada pihak tertentu.

4) Hanbaliyah mendefiniskan zakat adalah hak yang wajib pada harta tertentu kepada kelompok tertentu pada waktu tertentu.

\section{b. Infaq}

Menurut

$$
\text { pengertian }
$$

secara etimologis, infaq berasal dari kata "anfaqa" yang berarti mengeluarkan sesuatu (harta) untuk kepentingan sesuatu. Dalam terminologi syariat, infaq berarti mengeluarkan sebagian harta atau pendapatan penghasilan untuk suatu kepentingan yang diperintahkan oleh ajaran Islam. Jika zakat ada nisab-nya, maka infaq tidak mengenal nisab. Infak dikeluarkan oleh setiap orang yang beriman, baik yang berpenghasilan tinggi maupun rendah (Hafidhuddin, 2001: 15).

Infaq menurut Undang-Undang No. 23 Tahun 2011 adalah harta yang dikeluarkan oleh seseorang atau badan usaha di luar zakat untuk kemaslahatan umum. Lebih jauh, infaq dapat digunakan untuk kemaslahatan umum dan berarti sesuatu kewajiban yang dikeluarkan atas keputusan "manusia” (Inoed, 2005: 13).

\section{c. Shadaqah}

Shadaqah adalah suatu pemberian yang diberikan oleh seorang muslim kepada orang lain secara spontan dan sukarela tanpa dibatasi waktu dan jumlah tertentu, suatu pemberian yang diberikan oleh seseorang sebagai suatu kebajikan yang mengharap ridha Allah SWT dan pahala semata (Mursyid, 2006 :9).

Dalam terminologi syariah, pengertian shadaqah berarti mengeluarkan sebagian harta atau penghasilan untuk kepentingan yang diperintahkan ajaran Islam (Mufraini, 2006: 169).

Shadaqah yang sangat dianjurkan Islam adalah Shadaqah Jariyah, yakni shadaqah yang terus mengalir.Bagi jenis ini Islam telah memandang istimewa dari jenis shdaqah lainnya.Karena kelanggengan dari 
umat, pahalanya pun teru mengalir meski pelakunya sudah meninggal sealama manfaatnya masih dirasakan mereka (Qardlawi, 2010:180).

\section{Distribusi Dana Zakat}

Ada tiga hal yang perlu diperhatikan dalam memberikan pendistribusian zakat menurut Direktorat Pengembangan Zakat dan Wakaf Dirjen Bimas Islam dan Penyelenggara Haji Depag RI yaitu:

a. Zakat diberikan hanya kepada sasaran yang termasuk dalam delapan asnaf

b. Zakat tersebut dapat diterima dan dirasakan manfaatnya

c. Zakat sesuai dengan keperluan mustahiqq (konsumtif atau produktif).

Adapun sebagaimana yang dimaksud pada poin satu diantaranya adalah faqir, miskin, amil, muallaf, budak, ghorim, sabilillah, dan ibnu sabil.

a. Faqir

Orang yang tidak memiliki harta dan pekerjaan yang dapat mencukupi kebutuhannya. Dia juga tidak mempunyai pasangan (suami atau istri), orang tua dan keturunan yang dapat mencukupi kebutuhannya dalam menafkahinnya. Makanan, pakaian, dan tempat tinggalnya tidak tercukupi.

b. Miskin

Orang yang mampu untuk bekerja untuk menutupi kebutuhannya, namun belum mencukupi. Seperti orang yang membutuhkan sepuluh dan dia hanya mempunya delapan, sehingga tidak mencukupi kebutuhan sandang, pangan, dan papan.

c. Amil

Orang-orang yang bertugas mengumpulkan zakat. Bagi para amil disyaratkan adil, mengetahui fiqh zakat, masuk umur 10 tahun, dapat menulis, dapat membagi zakat kepada orang-orang yang berhak mendapatkannya, dan bisa menjaga harta.

d. Muallaf

Orang-orang yang baru memeluk agama Islam dan masih lemah keislamannya. Mereka diberi zakat agar keislaman mereka menjadi kuat.

e. Budak

Menurut ulama Syafi'iyah dan Hanafiyyah, mereka adalah budakbudak mukatab muslim yang tidak mempunyai harta untuk mencukupi apa yang sedang mereka lakukan, 
sekalipun sudah banting tulang dan memeras keringat untuk bekerja.

f. Ghorim

Orang-orang yang mempunyai banyak utang, baik seseorang itu berutang untuk dirinya sendiri maupun untuk orang lain.

g. Sabilillah

Para mujahid yang berperang yang tidak mempunyai hak dalam honor sebagai tentara, karena jalan mereka adalah mutlak berperang.

h. Ibnu Sabil

Orang yang bepergian atau orang yang hendak bepergian untuk menjalankan sebuah ketaatan bukan kemaksiatan. Kemudian dia tidak mampu mencapai tempat tujuannya melainkan dengan adanya bantuan (Al-Zuhaili, 2011: 280).

\section{Model Pendayagunaan Zakat}

Mohammad Daud Ali (1988) menawarkan empat jenis pendayagunaan atau pendistribusian dana zakat, antara lain:

a. Konsumtif tradisional, yakni zakat dibagikan kepada orang yang berhak menerimanya untuk dimanfaatkan langsung oleh yang bersangkutan, seperti zakat fitrah yang diberikan kepada fakir miskin untuk memenuhi kebutuhan sehari-hari atau zakat harta yang diberikan kepada korban bencana alam.

b. Konsumtif kreatif, yakni zakat diwujudkan dalam bentuk yang lain dari barangnya semula, misalnya diwujudkan dalam bentuk alat-alat sekolah, beasiswa dan lain-lain.

c. Produktif tradisional, yakni zakat yang diberikan dalam bentuk barang-barang produktif, misalnya kambing, sapi, mesin jahit, alat-alat pertukangan dan sebagainya. Pemberian zakat dalam bentuk ini akan dapat mendorong orang menciptakan suatu usaha atau memberikan suatu lapangan baru bagi fakir miskin.

d. Produktif kreatif, yakni pendayagunaan zakat yang diwujudkan dalam bentuk modal yang dapat dipergunakan, baik untuk membangun suatu proyek sosial baru maupun untuk membantu atau menambah modal pedagang atau pengusaha kecil.

Terdapat beberapa model pengembangan zakat yang dapat digunakan dalam penyalurkan zakat, antara lain:

\section{a. Surplus Zakat Budget}

Sistem pengembangan zakat dengan model surplus zakat budged adalah pengumpulan dana zakat yang kemudian dibagikan sebagian dan 
sisanya digunakan untuk proyekproyek produktif. Sistem ini dilengkapi dengan sistem zakat certifiate. Tujuan penerapan sistem ini adalah dana zakat yang dibagikan dan dalam bentuk sertifikat, maka uang yang cash akan digunakan atau dialokasikan untuk usaha atau proyek-proyek produktif sehingga mengalami perluasan usaha. Jika usaha mengalami perluasan, maka dapat menyerap tenaga kerja yang akan diambil dari golongan ekonomi lemah. Dengan demikian, melalui sistem ini akan terjadi pembukaan lapangan kerja dan akhirnya dapat mengurangi pengangguran di masyarakat. Keuntungan sistem ini adalah dibukanya lapangan kerja baru. Dana zakat tidak semuanya diterima dalam bentuk cash money, namun bisa berupa sertifikat yang sewaktu-waktu dapat dicairkan.

b. Sistem in Kind

Sistem in kind diterapakan dengan mekanisme dana zakat yang ada tidak dibagikan dalam bentuk uang apalagi dalam bentuk sertifkat. Namun dana zakat diberikan dalam bentuk alat-alat produksi yang dibutuhkan oleh kaum ekonomi lemah yang ingin berusaha, baik mereka yang baru akan memulai usahanya maupun yang telah berusaha untuk pengembangan usaha yang telah ada. Jika sistem ini diterapkan di Indonesia yang merupakan negara agraris, yaitu penduduk golongan menengah banyak yang berpekerjaan sebagai petani, maka sistem ini sangatlah tepat. Bagi kaum ekonomi lemah yang memiliki orientasi usaha sendiri, sistem ini juga tepat untuk dikembangkan.

\section{c. Revolving Fund}

Sistem revolving fund adalah sistem pengelolaan zakat dimana lembaga zakat memberikan pinjaman dana zakat kepada para mustahiq dalam bentuk pembiayaan qardhul hasan. Tugas mustahiq adalah mengembalikan dana pinjaman tersebut kepada lembaga zakat sebagian maupun sepenuhnya, tergantung pada kesepakatan awal. Melalui model ini, dana yang dikumpulkan oleh lembaga zakat akan dikelola secara bergulir dari mustahiq satu ke mustahiq lainnya, jika mustahiq yang dipinjami tersebut telah mengembalikan sebagian atau sepenuhnya dana pinjaman. Maksud sistem ini adalah melatih mustahiq mandiri dan 


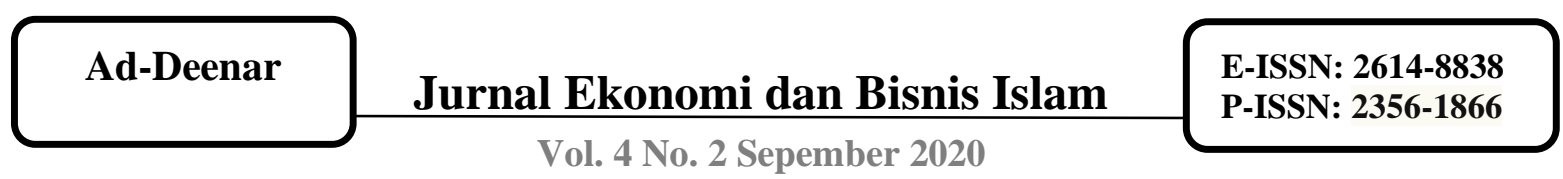

Vol. 4 No. 2 Sepember 2020

memiliki rasa tanggung jawab atas dana pinjaman yang diperolehnya. Selain itu, tujuan sistem ini adalah untuk pemerataan pendapatan sehingga zakat mampu menjadi alat pengentasan

kemiskinan

(Muhammad dan Ridwan Mas'ud, 2005: 57).

Pemberian modal yang dimaksud dalam poin tiga diatas dapat diberikan dalam dua bentuk, diantaranya:

a. Pemberian modal terhadap perorangan (Individu), pemberian modal kepada perorangan harus dipertimbangkan dengan matang oleh Amil. Apakah mampu orang tersebut mengolah dana yang diberikan itu, sehingga pada suatu saat dia tidak lagi menggantungkan hidupnya kepada orang lain.

b. Pemberian modal kepada perusahaan yang dikelola secara kolektif pemberian modal atas usaha yang dikelola secara kolektif ini, sekiranya dapat mengikut sertatakan orang-orang fakir miskin yang mampu bekerja menurut keahliannya masing-masing (Nawawi, 2010:84).

\section{METODE PENELITIAN}

Lokasi penelitian ini berada di Kota Madiun dengan sasaran Badan Amil Zakat
Nasional (BAZNAS) Kota Madiun.

Penelitian ini menggunakan metode deskriptif dengan pendekatan kualitatif, yakni metode penelitian yang digunakan untuk meneliti pada kondisi obyek yang amaliah, dimana peneliti adalah sebagai instrumen kunci (Sugiyono, 2008:1).

Kemudian penelitian ini memberikan gambaran tentang model pengelolaan zakat di lembaga berdasarkan hasil informasi yang diperoleh dari sumber data atau informan yang sudah valid. Jenis data penelitian dengan memanfaatkan jenis data primer dan sekunder. Dalam penelitian ini metode yang digunakan dalam pengumpulan data, yaitu antara lain: wawancara, observasi, dokumen dan pengamatan.

\section{PEMBAHASAN}

Kegiatan model pendayagunaan dana zakat, infaq, dan shadaqah di Badan Amil Zakat Nasional (BAZNAS) Kota Madiun berupa pendayagunaan distribusi konsumtif dan pendayagunaan distribusi produktif. Secara umum pendayagunaan distribusi konsumtif digolongkan menjadi tiga bagian diantaranya:

1. Pendayagunaan distribusi konsumtif berupa bantuan kepada dhuafa terkena musibah melalui program ACTD (Aksi Cepat Tanggap Darurat) dan sumbangan dana atau keperluan bahan 
pokok yang diperuntukkan kepada mustahiq yang tidak produktif melalui program Bantuan Paket Sembako, Bantuan Rutin Panti Asuhan, Bantuan Anak Yatim Piatu Non Panti Asuhan, Bantuan Ghorimin, dan Bantuan Ibnu Sabil.

2. Pendayagunaan distribusi konsumtif berupa bantuan kesehatan yang diwujudkan melalui program BPKD (Bantuan Penunjang Kesehatan Dhuafa).

3. Pendayagunaan distribusi konsumtif berupa bantuan pendidikan atau beasiswa melalui program Madiun Cerdas meliputi Bantuan Dana Belajar, Bantuan Alat Sekolah, dan Bantuan Dhuafa Berprestasi.

Jenis pendayagunaan distribusi pada poin satu merupakan kategori "Konsumtif Tradisional" yaitu zakat dibagikan untuk dimanfaatkan secara langsung oleh yang bersangkutan. Sedangkan jenis pendayagunaan distribusi pada poin dua dan tiga merupakan kategori "Konsumtif Kreatif" yaitu zakat diberikan dalam bentuk lain dari wujud semula (Ali, 1988: 64).

Adapun bentuk pendayagunaan distribusi produktif yang dilakukan oleh BAZNAS Kota Madiun dikemas dalam program Madiun Taqwa dan Madiun Makmur. Madiun Taqwa guna keperluan ibadah melalui Bantuan Guru Ngaji,
Bantuan Sarana Ibadah, dan Bantuan Muallaf.

Sedangkan Program Madiun Makmur menawarkan bantuan alat kerja meliputi Bina Usaha Dhuafa Mandiri, Koin Cinta Untuk Sesama, dan Bantuan Wirausaha Penyandang Difabel. Syarat dan kriteria utama Program Madiun Makmur adalah dhuafa yang mempunyai usaha kecilkecilan yang berasal atau berdomisili di Kota Madiun

Adapun jenis program Madiun Makmur menggunakan surplus zakat budged, dimana pengumpulan dana zakat yang kemudian dibagikan sebagian dan sisanya digunakan untuk proyek-proyek produktif. Sistem ini dilengkapi dengan sistem zakat certifiate. Tujuan penerapan sistem ini adalah dana zakat yang dibagikan dan dalam bentuk sertifikat, maka uang yang cash akan digunakan atau dialokasikan untuk usaha atau proyekproyek produktif sehingga mengalami perluasan usaha. Jika usaha mengalami perluasan, maka dapat menyerap tenaga kerja yang akan diambil dari golongan ekonomi lemah. Dengan demikian, melalui sistem ini akan terjadi pembukaan lapangan kerja dan akhirnya dapat mengurangi pengangguran di masyarakat. Keuntungan sistem ini adalah dibukanya lapangan kerja baru. Dana zakat tidak semuanya diterima dalam bentuk cash money, namun bisa 
berupa sertifiat yang sewaktu-waktu dapat dicairkan.

Selain menggunakan jenis surplus zakat budged, program Madiun Makmur menggunakan jenis sistem in kind dimana mekanisme dana zakat yang ada tidak dibagikan dalam bentuk uang apalagi dalam bentuk sertifkat. Namun dana zakat diberikan dalam bentuk alat-alat produksi yang dibutuhkan oleh kaum ekonomi lemah yang ingin berusaha, baik mereka yang baru akan memulai usahanya maupun yang telah berusaha untuk pengembangan usaha yang telah ada (Muhammad dan Ridwan, 2005: 57). Contohnya pemberian bantuan alat kerja berupa gerobak, etalase, dan rombong.

\section{E. KESIMPULAN}

Penerapan model pendayagunaan dalam memanfaatkan dana zakat, infaq, dan shadaqah yang dilakukan oleh Badan Amil Zakat Nasional (BAZNAS) Kota Madiun adalah sebagai berikut:

1. Model pendayagunaan konsumtif yang dilakukan oleh Baznas Kota Madiun yakni dikategorikan menjadi dua macam: pertama, Konsumtif Tradisional, yakni penyaluran yang diberikan secara langsung dalam wujud asalnya, yang seperti bantuan musibah atau bencana dan pemberian berupa sembako. Kedua, Konsumtif Kreatif, yakni penyaluran yang dirupakan dalam bentuk yang lain atau bukan bentuk asalnya, seperti bantuan kesehatan dan pendidikan.

2. Model pendayagunaan distribusi produktif, khususnya program Madiun Makmur BAZNAS Kota Madiun menggunakan surplus zakat budged, yang dalam prakteknya BAZNAS memberikan digunakan untuk proyekproyek produktif. Dan juga menggunakan jenis sistem in kind dimana mekanisme dana zakat yang ada tidak dibagikan dalam bentuk uang apalagi dalam bentuk sertifkat. Namun dana zakat diberikan dalam bentuk alat-alat produksi seperti gerobak, etalase, dan rombong.

\section{Saran}

Bagi pemerintah diharapkan membuka akses yang lebar untuk keterlibatan lembaga-lembaga amil zakat dalam proses perencanaan, pelaksanaan serta evaluasi program pengentasan kemiskinan di Kota Madiun hal tersebut merupakan upaya untuk mensinergikan pengelolaan zakat dengan program pengentasan kemiskinan dan pemerintah diharapkan lebih membantu program pemberdayaan masyarakat yang tidak mampu, yang diadakan oleh lembaga zakat, baik program yang besar maupun program yang kecil. 


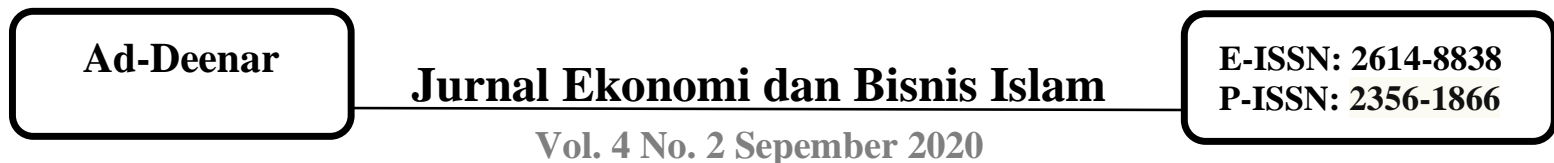

Bagi Badan Amil Zakat Nasional (BAZNAS) Kota Madiun diharapkan lebih memaksimalkan potensi lokal yang dimiliki, diantaranya dengan menjalin kerjasama dengan berbagai lembaga yang berkaitan demi pemberdayaan ekonomi. Dan juga diharapkan mengotimalkan pembinaan kepada mustahiq dan meningkatkan sistem monitoringnya.

\section{DAFTAR PUSTAKA}

Ali, Mohammad Daud. (1988). Sistem Ekonomi Islam: Zakat dan Wakaf, (Jakarta: UI Press.

Al-Zuhaili, Wahbah. (1995). Zakat: Kajian Berbagai Mazhab, (Bandung: Remaja Rosdakarya.

Al-Zuhaili, Wahbah. (2011). Fiqh AlIslamy Wa Adillatuh Jilid III, (Jakarta: Gema Insani.

Direktorat Pengembangan Zakat dan Wakaf Dirjen Bimas Islam dan Penyelenggara Haji Depag RI. 2003. Pedoman Zakat.

Fahami Muhammad Anis dan Salina H. Kassim. (2016). Effectiveness Of Zakat-Based Programs On Poverty Alleviation And Economic Empowerment Of Poor Women: A Case Study Of Bangladesh. (Journal of Islamic Monetary Economics and Finance, 1(2).

Hafidhuddin, Didin. (2011). Panduan Praktis Tentang Zakat, Infaq, dan Shadaqah. Jakarta: Gema Insani Press.

Hidayat, Mansur. (2014). Pola Pendayagunaan Zakat dalam Pemberdayaan Sosial Ekonomi Ummat. Jurnal Ilmu Dakwah dan Pengembangan Komunitas, 9(2).

Inoed, Amiruddin, dkk. (2005). Anatomi Fiqh Zakat: Potret \& Pemahaman
Badan Amil Zakat Sumatera Selatan. Yogyakarta: Pustaka Pelajar.

Kartika Sari, Elsi. (2007). Pengantar Hukum Zakat dan Wakaf. Jakarta: PT Grasindo.

Khasanah, Umrotul. (2010). Manajemen Zakat Modern, (Malang: UIN Maliki Press.

Mufraini, Arif. (2006). Akuntansi dan Manajemen Zakat. (Mengkomunikasikan Kesadaran dan Membangun Jaringan). Jakarta: Kencana Prenada Media Group.

Muhammad dan Ridwan Mas'ud. (2005). Zakat dan Kemiskinan: Instrumen Pemberdayaan Ekonomi Umat. Yogyakarta: UII Press.

Mursyid. (2005). Mekanisme Pengumpulan Zakat, Infaq, dan Shadaqah: menurut Hukum Syara' dan undang-Undang. Yogyakarta: Magister Insania Press.

Nawawi, Ismail. (2010). Zakat dalam Perspektif Fiqh, Sosial, dan Ekonomi. Surabaya: ITS Press.

Pilayanti, Indah. (2010). Transformasi Tradisi Filantropi Islam: Studi Model Pendayagunaan Zakat, Infaq, Sadaqah Waqaf di Indonesia. Economica. Nomor 11. Edisi 11.

Qardhawi, Yusuf. (2010). Shadaqah Cara Islam Mengentaskan Kemiskinan, Bandung: PT Remaja Rosdakarya.

Sugiyono, Memahami Penelitian Kualitatif, (Bandung: CV Alvabeta, 2008).

Tri Puspa Ningrum, Ririn, Penerapan Manajemen Zakat dengan Sistem Revolving Fund Models Sebagai Upaya Efektifitas Penyaluran Zakat Produktif (Studi pada Lembaga Manajemen Infaq Madiun). (ElWasathiya: Jurnal Studi Agama Volume 4, 2016) p-ISSN 2338-9648.eISSN: 2527631X.

Undang-Undang No. 23 Tahun 2011 
